\title{
Pengetahuan dan Sikap Siswa SMA dalam Menghadapi Bencana Gempa Bumi
}

Felive R.D.C. Pasaribu, Mori Agustina br Perangin-angin

Fakultas Ilmu Keperawatan, Universitas Advent Indonesia, Jl. Kolonel Masturi No.288, Cihanjuang Rahayu, Kecamatan Parongpong, Kabupaten Bandung Barat, Jawa Barat

Email: linopasaribu7@gmail.com

$\begin{array}{ll}\text { Diterima tanggal } & : \text { 01 Mei } 2020 \\ \text { Direvisi tanggal } & : \text { 21 Mei } 2020 \\ \text { Dipublikasikan tanggal } & : \text { 11 Juni } 2020\end{array}$

\begin{abstract}
Abstrak
Latar Belakang dan Tujuan: Salah satu faktor yang menyebabkan begitu banyak korban yang jatuh ketika terjadi bencana gempa bumi dikarenakan kurangnya pengetahuan yang dimiliki oleh masyarakat. Tujuan dari penelitian ini adalah untuk menggali tingkat pengetahuan dan sikap yang di miliki oleh siswa dalam menggahadapi bencana gempa bumi.

Metode: Deskriptif korelasi dengan pendekatan cross sectional. Penelitian dilakukan di Sekolah Advent Nias. Populasi pada penelitian ini adalah siswa kelas 12. Teknik sampling menggunakan total sampling. Instrumen yang digunakan adalah kuesioner. Analisis data menggunakan korelasi spearman rho.

Hasil: Rerata usia responden adalah 17 tahun sebanyak 17 (53\%), sebagian besar jurusan MIA A 34 (25,4\%), tingkat pengetahuan sebagian besar cukup 86 $(64,2 \%)$, sikap sebagian besar negatif $101(75,4 \%)$, hasil uji statistik menunjukkan nilai $\mathrm{p} 0,000<0,05$ yang berarti ada hubungan antara pengetahuan dan sikap siswa dalam menghadapi bencana gempa bumi.

Simpulan dan Implikasi Pengetahuan yang dimiliki oleh siswa SMA di Perguruan Advent Nias dalam kategori cukup, namun masih belum bisa untuk mengambil sikap yang tepat untuk menghadapi bencana gempa bumi. Sementara sikap yang di miliki oleh murid di Perguruan Advent Nias dalam menghadapi bencana gempa bumi masih dalam kategori rendah. Untuk meningkatkan pengetahuan dan sikap siswa dalam menghadapi bencana maka perlu diadakan pelatihan atau sosialisasi.
\end{abstract}

Kata Kunci: Gempa Bumi; Pengetahuan; Sikap

Sitasi: Pasaribu F R D C \& Perangin-angin M A. (2020). Pengetahuan dan sikap siswa SMA dalam menghadapi bencana gempa bumi. The Indonesian Journal of Health Science. 12(1), 76-82

Copyright: () 2020 Pasaribu et al. This is an open-access article distributed under the terms of the Creative Commons Attribution License, which permits unrestricted use, distribution, and reproduction in any medium, provided the original author and source are credited.

Diterbitkan Oleh: Universitas Muhammadiyah Jember

ISSN (Print): 2087-5053

ISSN (Online): 2476-9614 


\begin{abstract}
Background and Aim: One of the factors that caused many victims to fall during an earthquake is due to the lack of knowledge possessed by the community. The purpose of this study was to explore the level of knowledge and attitudes possessed by students

Method: Descriptive correlation with cross sectional approach. The research was conducted at the Nias Adventist School. The population in this study were students in grade 12. The sampling technique used total sampling. The instrument used was a questionnaire. Data analysis used Spearman rho correlation.

Results: The mean age of the respondents was 17 years old as many as 17 (53\%), most of the MIA A majors were 34 (25.4\%), the level of knowledge was mostly quite $86(64.2 \%)$, attitudes were mostly negative 101 (75.4\%), the results of statistical tests showed $p$ value $0.000<0.05$, which means that there is a relationship between students' knowledge and attitudes in dealing with earthquakes.

Conclusion: The results of this study indicate the knowledge possessed by high school students at Nias Adventist School is in the sufficient category, but they are still unable to take the right attitude to face the earthquake disaster. Meanwhile, the attitude of students at Nias Adventist College in facing the earthquake is still low. To increase students' knowledge and attitudes in dealing with disasters, it is necessary to hold training or socialization.
\end{abstract}

Keywords: Attitude; Earthquake; Knowledge.

\section{PENDAHULUAN}

Bencana merupakan peristiwa yang terjadi dikarenakan faktor alam ataupun faktor non alam yang dapat mengancam kehidupan manusia. Negara Indonesia di kelilingi oleh Cincin Api Pasific dan berada di atas 3 tumbukan lempeng yang menyebabkan Indonesia menjadi negara yang sangat rawan untuk terkena bencana gempa bumi (Esperanza \& Simanjuntak, 2019). Gempa bumi merupakan sebuah guncangan hebat yang disebabkan karna terjadinya gangguan di dalam kulit bumi dan guncangan tersebut menjalar hingga ke permukaan bumi (Mustafa, 2010).

Kabupaten Nias merupakan salah satu kabupaten dalam wilayah Provinsi Sumatera Utara dan berada di sebelah Barat Pulau Sumatera. Pulau Nias terbentuk dikarenakan terjadi tumbukan antara 2 lempeng benua Eurasia dan lempeng Hindia. Akibat tumbukan ini maka sangat tinggi potensi untuk terjadinya gempa bumi di Nias (Dinkes Kabupaten Nias Selatan, 2013).

Menurut Levitasari, Laila Nugraha, \& Janu Amarrohman, (2017), gempa bumi terparah di Sumatera terjadi pada tanggal 28 Maret 2005 pukul 23.09 WIB yang berkekuatan sebesar 8,7 skala richter dan Pusat gempanya berada di $2^{\circ} 04^{\prime}$ $35^{\prime \prime}$ LU 97 00' 58" BT, $30 \mathrm{~km}$ dibawah permukaan Samudra Hindia. Diperkirakan korban jiwa tercatat lebih dari 1.000 orang meninggal, lebih dari 2.391 orang luka-luka di Pulau Nias, dan begitu banyak bangunan dan fasilitas umum yang rusak dan runtuh.

Menurut data statistik BNPB, pada tahun 2019 telah terjadi gempa 
bumi sebanyak 70 kali, dimana korban yang meninggal sebanyak 22 orang, luka - luka 286 orang, terdampak dan mengungsi sebanyak 78,598 orang, serta ribuan bangunan mengalami kerusakan (Badan Nasional Penanggulangan Bencana, 2019). Kesiapsiagaan terhadap bencana merupakan prilaku kesehatan yang harus kita miliki sehingga kita dapat melindungi diri kita, dan orang di sekitar kita (Esperanza \& Simanjuntak, 2019). Salah satu faktor yang menyebabkan banyaknya korban ketika terjadi sebuah bencana adalah karena kurangnya pengetahuan yang dimiliki masyarakat akan bencana tersebut, oleh karena itu sangat penting bagi kita untuk mempersiapkan diri kita dengan menambah wawasan atau pengetahuan kita akan bencana tersebut dan meningkatkan kesiapsiagaan kita untuk memperkecil resiko untuk terjadinya korban.

Namun dari hasil penelitian menunjukkan bahwa masyarakat masih kurang pengetahuan tentang kesiapanmenghadapi bencana. Penelitian yang dilakukan oleh Hesti, Yetti, \& Erwani, (2019) menunjukkan bahwa lebih dari setengah $(52,1 \%)$ responden belum siap untuk menghadapi bencana gempa bumi. Hasil penelitian Rosida \& Adi, (2017) juga menunjukkan bahwa karna kurangnya pengetahuan yang dimiliki oleh responden maka sikap yang ditunjukkan dalam kategori kurang baik . Nias merupakan salah satu tempat yang sangat rawan akan bencana gempa bumi oleh karna itu dengan mengetahui seberapa baik pengetahuan dan sikap yang di miliki oleh siswa di Perguruan Advent nias maka reneliti dapat mengetahui dan mengukur apakah Siswa di Perguruan Advent nias siap untuk menghadapi bencana gempa bumi.

\section{METODE PENELITIAN}

Penelitian ini menggunakan metode deskriptif korelasi dengan pendekatan cross sectional. Populasi adalah murid kelas 12 tahun ajaran 2020/2021 sebanyak 159 orang di Perguruan Advent Nias. Teknik pengambilan sampel yang di gunakan dalam penelitian ini adalah total sampling. Instrumen yang digunakan adalah kuesioner yang berisi pertanyaan yang digunakan untuk memperoleh informasi dari responden yang berkaitan dengan pengetahuan dan sikap responden terhadap bencana gempa bumi. Kuesioner pada penelitian ini berisi 24 butir pertanyaan yang dibagi menjadi 2 bagian yaitu 12 butir pertanyaan mengenai pengetahuan dan 12 butir mengenai sikap. Dari 159 kuesioner yang dibagikan, terdapat 10 orang yang menolak untuk berpartisipasi dan tidak mengikuti kegiatan penelitian ini dan terdapat 15 responden yang menjawab kuesioner dengan tidak lengkap sehingga tidak diikutsertakan menjadi sampel, sehingga jumlah sampel dalam penelitian ini adalah 134 orang. Pengumpulan data dilakukan secara online yang dikirim via whatsapp.

\section{HASIL}

Tabel 1 menunjukkan bahwa berdasarkan kelompok usia, terdapat $62 \%$ responden berusia $16-17$ tahun, dan $38 \%$ berusia $18-20$ tahun. Sementara berdasarkan jurusan, responden paling banyak berasal dari jurusan MIA - A 
sebanyak 34 orang $(25,4 \%)$. Jurusan MIA merupakan singkatan dari Matematika Dan Ilmu Alam atau bisa kita kenal dengan jurusan IPA sementara Jurusan IIS merupakan singkatan dari Ilmu Ilmu Sosial atau biasa kita kenal dengan IPS. Tabel 2 menunjukkan tingkat pengetahuan responden untuk kesiapsiagaan bencana gempa. Dapat dilihat yang paling mendominasi adalah siswa dengan pengetahuan yang cukup $(64,2 \%)$ kemudian diikuti oleh siswa dengan kategori baik $(22,4 \%)$, dan terakhir siswa dengan kategori kurang (13,4\%). Tabel 3 menunjukkan sikap dari para responden terhadap bencana gempa bumi. Dapat di lihat 75,4 \% responden memiliki sikap yang negatif atau tidak siap, sementara hanya terdapat $24,6 \%$ memiliki sikap positif atau siap terhadap bencana gempa bumi.

Tabel 4 menunjukkan terdapat hubungan antara tingkat pengetahuan dan sikap dengan nilai $\mathrm{p} 0,000$ di mana nilai tersebut lebih rendah daripada nilai $\alpha(0,05)$. Dengan demikian dapat dipastikan terdapat hubungan antara tingkat pengetahuan dan sikap siswa kelas 12 SMA Perguruan Advent Nias dalam menghadapi bencana gempa bumi.

Tabel 1. Karakteristik Responden

\begin{tabular}{|c|c|c|c|}
\hline Karakteristik & & Frekuensi & Persentase (\%) \\
\hline \multirow[t]{5}{*}{ Umur } & 16 & 12 & 9 \\
\hline & 17 & 71 & 53 \\
\hline & 18 & 37 & 27,6 \\
\hline & 19 & 12 & 9 \\
\hline & 20 & 2 & 1,5 \\
\hline \multirow[t]{6}{*}{ Jurusan } & MIA A & 34 & 25,4 \\
\hline & MIA B & 31 & 23,1 \\
\hline & MIA C & 22 & 16,4 \\
\hline & ISS A & 29 & 21,6 \\
\hline & ISS B & 18 & 13,4 \\
\hline & Total & 134 & 100 \\
\hline
\end{tabular}

Tabel 2. Tingkat Pengetahuan Siswa tentang Bencana Gempa Bumi

\begin{tabular}{ccc}
\hline Kategori & Frekuensi & Persentase $(\%)$ \\
\hline Kurang & 18 & 13,4 \\
Cukup & 86 & 64,2 \\
Baik & 30 & 22,4 \\
\hline Total & 134 & 100 \\
\hline
\end{tabular}

Tabel 3. Sikap Siswa terhadap Bencana Gempa Bumi

\begin{tabular}{ccc}
\hline Sikap & Frekuensi & Persentase (\%) \\
\hline Positif & 33 & 24,6 \\
Negatif & 101 & 75,4 \\
\hline Total & 134 & 100
\end{tabular}

Tabel 4. Hubungan tingkat pengetahuan dan sikap

\begin{tabular}{cccc}
\hline Variabel Independen & Variabel Dependen & $P$ Value & r \\
\hline Pengetahuan & Sikap & 33 & 0,680 \\
\hline
\end{tabular}




\section{PEMBAHASAN}

Pengetahuan merupakan sesuatu yang di hasilkan dari pengindraan, atau sesuatu yang diketatahui seseorang terhadap objek melalui panca indra yang dimiliki (Fakhrurrazi, Mulyadi, \& Ismail, 2015). Dengan pengetahuan yang cukup maka seseorang akan lebih mudah untuk berfikir bagaimana cara mengatasi apa yang di hadapkan kepadanya. Pengetahuan yang dimiliki oleh siswa SMA di Perguruan Advent Nias dalam penelitian ini cukup baik, mungkin karna dengan banyaknya informasi yang dapat mereka temukan dari berbagai media membuat pengetahuan mereka sangat baik. Namun sangat disayangkan karna masih terdapat siswa dengan kategori kurang pengetahuan akan bencana. Pengetahuan responden mengenai bencana yang baik juga digambarkan dalam penelitian yang di lakukan oleh Daud, Sari, Milfayetty, \& Dirhamsyah, (2014) yang menyatakan aspek pengetahuan tentang kesiapsiagaan bencana secara umum berada dalam kategori sangat bagus dengan rata rata jumlah responden yang menjawab pertanyaan dengan benar sebanyak 75\%. Sementara hasil berbanding terbalik dengan penelitian yang di lakuakn oleh Kurniawati \& Suwito, (2019) yang menyatakan sebanyak $74,4 \%$ siswa memiliki pengetahuan yang termasuk dalam kategori kurang dengan nilai rata rata pengetahuan siswa tersebut sebanyak 29,82 .

Menurut Firmansyah, Rasni, \& Rondhianto, (2014), pendidikan kesehatan dengan tujuan meningkatkan pengetahuan merupakan hak yang harus didapatkan oleh setiap masyarakat.
Diharapkan dengan adanya pemaparan materi tentang bencana gempa bumi dapat meningkatkan pengetahuan para siswa SMA Perguruan Advent Nias sehingga mereka dengan pengetahuan yang kurang dapat di tingkatkan pengetahuannya. Menurut Setiawati, Utami, \& Sabrian, (2020), pengetahuan merupakan salah satu hal yang dapat mempengaruhi cara berfikir seseorang untuk mengambil sebuah tindakan atau sikap. Budimanto, Mudatsir, \& Tahlil, (2017) juga menyatakan setiap individu harus memiliki pengetahuan mengenai bencana gempa dan pemahaman bagaimana cara menyelamatkan diri dalam keadaan tersebut. Semakin tinggi atau rendah pengetahuan maka akan semakin mempengaruhi baik atau buruknya orang dalam mengambil sebuah tindakan atau sikap.

Sikap merupakan reaksi yang di keluarkan seseorang terhadap stimulus atau objek (Mojokerto, 2018). Sikap yang dihasilkan juga dapat berupa sikap positif dan negatif. Dari data ini kita lihat banyak siswa yang belum mengerti bagaimana untuk bersikap yang tepat ketika dihadapkan kepada keadaan tersebut. Hal ini mungkin terjadi karna pengetahuan mereka yang cukup namun masih berada dalam kategori rendah, bukan hanya itu saja kurangnya pengalaman yang mereka miliki juga dapat mempengaruhi bagaimana sikap yang mereka ambil. Hal ini di dukung oleh penelitian yang dilakukan oleh Rosida \& Adi, (2017) yang menyatakan orang mungkin tidak akan mengetahui bagaimana cara mengurangi resiko bencana apabila belum pernah memiliki pengalaman mengenai bencana tersebut. Buruknya sikap 
yang diambil oleh seseorang dapat memberikan dampak yang buruk berupa cidera, luka, bahkan kematian. Rasa panik yang di dalam diri seseorang juga dapat memperngaruhi sikap yang akan di ambil, rasa panik dapat membuat kita yang seharusnya memiliki sikap atau reaksi positive menjadi negativf. Purwoko (2015) menyatakan bahwa pengetahuan merupakan hal yang menentukan bagaimana kita berprilaku atau menetukan sikap kita. Dengan demikian setiap manusia perlu untuk memperbanyak dan meningkatkan pengetahuannya sehingga dapat berprilaku dengan baik dan benar

\section{SIMPULAN}

Pengetahuan siswa mempunyai hubungan yang erat dengan sikap siswa dalam menghadapi bencana gempa gumi. Semakin baik pengetahuan siswa tentang gempa bumi maka semakin positif sikap yang dimiliki dalam menghadapi bencana gempa bumi.

\section{SARAN}

Pengetahuan yang di miliki oleh para siswa SMA di Perguruan Advent Nias masih perlu untuk di tingkatkan. Diharapkan agar pihak sekolah memberikan promosi kesehatan tentang bencana gempa bumi sehingga dengan adanya pemberian promosi kesehatan tersebut pengetahuan yang di miliki oleh siswa ini dapat menjadi lebih baik lagi khususnya mengenai bencana gempa bumi. Selain itu diharapkan pihak sekolah memberikan pelatihan simulasi akan bancana gempa kepada siswa sehingga pada saat yang akan dating ketika siswa tersebut di hadapkan dalam keadaan tersebut maka siswa sma advent nias dapat mengambil tindakan yang lebih baik lagi.

\section{DAFTAR PUSTAKA}

Badan Nasional Penanggulangan Bencana. (2019). Data Informasi Bencana Indonesia. Retrieved September 15, 2020, from https://bnpb.cloud website:

https://bnpb.cloud/dibi/laporan $5 \mathrm{a}$

Budimanto, Mudatsir, \& Tahlil, T. (2017). Hubungan Pengetahuan, Sikap Bencana Dan Keterampilan Basic Life Support Dengan Kesiapsiagaan Bencana Gempa Bumi Pada Mahasiswa Keperawatan Poltekkes Banda Aceh. Ilmu Kebencanaan, 4(2), 53-58.

Daud, R., Sari, S. A., Milfayetty, S., \& Dirhamsyah, M. (2014). Penerapan Pelatihan Siaga Bencana Dalam Meningkatkan Pengetahuan, Sikap, Dan Tindakan Komunitas Sma Negeri 5 Banda Aceh. Ilmu Kebencanaan, 1(1), 26-34.

Dinkes Kabupaten Nias Selatan. (2013). Profil Kabupaten Nias Selatan. 66-81.

Esperanza, A., \& Simanjuntak, S. M. (2019). Pengetahuan tentang Kesiagaan Bencana Melalui Promosi dan Pelatihan Siaga Gempa Bumi Pendahuluan Indonesia berada di jalur gempa teraktif di dunia karena dikelilingi oleh Cincin Api Pasifik dan berada di atas tiga tumbukan lempeng benua , yakni , Indo-Aus. 3(1), 1-14.

Fakhrurrazi, Mulyadi, \& Ismail, N. (2015). Pengetahuan Dan Sikap Tenaga Kesehatan 
Rumah Sakit Umum Daerah (Rsud) Pidie Jaya Terhadap Kesiapsiagaan Dalam Menghadapi Risiko Bencana Banjir. Jurnal Ilmu Kebencanaan: Program Pascasarjana Unsyiah, (Vol 2, No 4: November 2015), 1-12. Retrieved from http://www.jurnal.unsyiah.ac.id /JIKA/article/view/8152

Firmansyah, I., Rasni, H., \& Rondhianto. (2014). Hubungan Pengetahuan dengan Perilaku Kesiapsiagaan dalam Menghadapi Bencana Banjir dan Longsor pada Remaja Usia 15-18 tahun di SMA Al-Hasan Kemiri Kecamatan Panti Kabupaten Jember. Universitas Jember, 1, 1-8. Retrieved from http://repository.unej.ac.id/bitst ream/handle/123456789/60652
/Iman

Firmansyah.pdf?sequence $=1$

Hesti, N., Yetti, H., \& Erwani, E (2019). Faktor-Faktor yang berhubungan dengan Kesiapsiagaan Bidan dalam Menghadapi Bencana Gempa dan Tsunami di Puskesmas Kota Padang. Jurnal Kesehatan Andalas, $\quad 8(2), \quad 338$ https://doi.org/10.25077/jka.v8 i2.1010

Kurniawati, D., \& Suwito, S. (2019). Pengaruh Pengetahuan Kebencanaan Terhadap Sikap Kesiapsiagaan Dalam Menghadapi Bencana Pada Mahasiswa Program Studi Pendidikan Geografi Universitas Kanjuruhan Malang. JPIG (Jurnal Pendidikan Dan Ilmu Geografi), 2(2). 